Nancy Chick, VANDERBILT UNIVERSITY, nancy.chick@vanderbilt.edu

Gary Poole, UNIVERSITY OF BRITISH COLUMBIA, gpoole@exchange.ubc.ca

\title{
INTRODUCTION
}

\section{Launching TLI: SoTL's Purposes, Processes, and People}

Nearly a decade of vision, planning, and hard work has led to the words on these pages. Since the early days of the International Society for the Scholarship of Teaching and Learning (ISSOTL), many members and officers have been eager for a journal officially sponsored by the Society as a benefit of membership, a standard of quality in the field, and a complement to the annual conference. Despite the success of its conferences and an increasingly active membership, the Society waited strategically until a distinct vision was proposed, the right editorship was selected, and a relationship with a university press was secured.

We believe that there is a need within the field for another SoTL journal, one with a unique relationship with ISSOTL and a university press. We are honored to be the first and only journal carrying the official sponsorship of ISSOTL, and we are fortunate to be working with Indiana University Press in the publication of the journal. The first and fifth ISSOTL conferences were held on the Indiana University campus, and-in addition to its long and impressive history of presenting important scholarship_-IU Press's publication of TLI complements its more recent commitment to SoTL with its SoTL book series, which began in 2009.

As we explain in our mission statement, Teaching \& Learning Inquiry will publish insightful research, theory, commentary, and other scholarly works that document or facilitate investigations of teaching and learning in higher education. It values quality and variety in its vision of the Scholarship of Teaching and Learning. With Nancy's background in literary studies and Gary's in psychology, we as co-editors are committed to ensuring that the journal's pages will showcase the breadth of the interdisciplinary field of SoTL in its explicit methodological pluralism, its call for traditional and new genres, and its international authorship from across career stages. TLI embraces creative as well as traditional approaches to understanding teaching and learning and ways to share that understanding. Ultimately, TLI will be a beacon for such high-quality work that includes and even calls attention to both more traditional models and those not traditionally seated at the SoTL "family table" (Shulman 2006).

Our first task as editors was to build a strong Editorial Board, prioritizing coverage of all ISSOTL's regions (the United States, Canada, Australasia, and Europe), the whole career spectrum (from students to retired faculty, and all in between), a breadth of disciplines and professions, a variety of institutional types, and a balance of women and 
men. The support and wisdom of this group has quickly become the foundation of all of our work, instrumental in the major decisions to date. For example, after much brainstorming, parsing, debating, and voting, they named the journal. They carefully considered the politics and nuances of SoTL work as they honed our reviewer selection process and reviewer guidelines. They are currently discussing some fundamental principles of "good SoTL" in an online conversation that will appear later as a follow-up to one of our invited pieces in this inaugural issue.

This inaugural issue consists of invited pieces and member submissions answering our call to "explore SoTL's traditions or its cutting edges, its highest moments or the challenges that remain, its efforts to go public or its impacts in campus classrooms or hallways, its relevant constituencies or its unexplored audiences." Two themes emerged from the final selection: nine essays considering the benefits of SoTL to specific audiences and contexts, and five essays articulating ways of advancing SoTL.

The first set of essays describes what SoTL and its practitioners offer specific audiences and contexts - starting broadly with SoTL's service to higher education in general, then narrowing the focus to campuses, faculty developers, faculty, and finally students and student learning. In "The Transformative Potential of The Scholarship of Teaching," Carolin Kreber argues that SoTL's ultimate service is to enhance social justice via the improvement of higher education. In "Validity through Dialogue," ISSOTL's first President Barbara Cambridge considers the role of ISSOTL and now Teaching and Learning Inquiry as agents of change in higher education. Both offer a rare range and depth of expertise built on "reflective openness," or the recognition of multiple, valid perspectives. Those who've attended an ISSOTL conference cite these qualities as hallmarks of the yearly event, often describing it as a transformative experience based on such interactions with new and old colleagues from a range of disciplines and nationalities. In "A New Scholarship of Classroom-Based, Open, Communal Inquiry?," Jan Parker advocates for a vital integrative role for SoTL, bringing Boyer's scholarships together to create a new model for classroom teaching and learning that yields communities of inquiry fueled by skills of inquiry, curiosity, and lifelong learning.

The ISSOTL conference lasts just a few days each year, and not all ISSOTL members can attend. Most of our professional work occurs on our campuses, away from the larger SoTL community and in a setting less likely to recognize the value of SoTL. Dan Bernstein, ISSOTL's current President, articulates what SoTL practitioners offer campuses, especially those with greater emphasis on research, in "How SoTL-Active Faculty Members Can Be Cosmopolitan Assets to an Institution.” Faculty who practice SoTL offer the campus community and prospective students strong models for instructional design, assessment of student learning, and excellent teaching with attention to student learning. In "SoTL Inquiry in Broader Curricular and Institutional Contexts: Theoretical Underpinnings and Emerging Trends," Harry Hubball, Marion L. Pearson, and Anthony Clarke extend the usefulness of SoTL in its potential for curricular practice and reform. They call this specific form of SoTL "the Scholarship of Curricular Practice" (SoCP) and offer a framework for how departments, programs, or units can revise curricula and other institution-wide programs.

In this local context of our campuses, we seek out colleagues equally interested in inquiry into student learning, often through faculty development programs. In "Going Public with Pedagogical Inquiries: SoTL as a Methodology for Faculty Professional De- 
velopment," Joëlle Fanghanel, ISSOTL's President-Elect, argues that SoTL offers an alternative and more faculty-friendly model of faculty development that replaces the pervasive model based on competition, outputs, performativity, and solitude with one that's democratic, dialogic, process-focused, and collaborative. Linda Hodges, like Fanghanel, describes SoTL as an effective model for faculty development in "Postcards from the Edge of SoTL: A View from Faculty Development"; however, Hodges focuses on how SoTL gives faculty developers a more systematic and informed way to help their faculty think about their work as teachers and their students' work as learners. Illustrating these dynamics, ISSOTL Treasurer Barbara Mae Gayle, former Canadian Vice President Nancy Randall, Lin Langley, and Raymond Preiss's "Faculty Learning Processes: A Model for Moving from Scholarly Teaching to the Scholarship of Teaching and Learning" offers a specific description of what SoTL as faculty development looks like. They explore how faculty members come to learn the methods and culture of SoTL in order to become what Kreber and Hoyle call "extended" practitioners and knowledgeable consumers of SoTL research. Finally, they propose a multi-stage model that traces a faculty member's development from a teacher-centered to more inquiry-based approach to teaching.

The last subset of essays addressing SoTL's benefits to specific audiences focuses its lens to students, a particularly important perspective given the ultimate goal of improving student learning. ISSOTL Co-President from 2007 to 2009 Keith Trigwell's "Evidence of the Impact of Scholarship of Teaching and Learning Purposes" reports the findings of a study measuring the effectiveness of SoTL in improving student learning. He concludes that, when a specifically defined SoTL perspective is adopted, student learning increases. Phillip Dawson, Margaret Bearman, David J. Boud, Matt Hall, Elizabeth K. Molloy, Sue Bennett, and Gordon Joughin also address student learning in "Assessment Might Dictate the Curriculum, But What Dictates Assessment?" Calling attention to the gap between what is known about best practice in assessment design and what is actually practiced, Dawson and colleagues analyze these decision-making processes to help us better understand this gap.

The second set of essays selected for the inaugural issue of TLI explores ways to advance SoTL and the conversations about it. No longer a new movement, SoTL is now mature enough to consider how we might fill in its early gaps and stretch beyond its growing pains. In "One Important Lesson I've Learned from My Involvement with SoTL," Joy Mighty reminds us that, for SoTL to move forward, it must have strong support by the leadership (formal and informal) on campuses, in disciplinary societies, and in educational development. Reaching beyond familiar genres, Lorraine Gilpin's poem "SoTL in Verse" outlines a multi-layered set of characteristics that define SoTL. Her specific poetic form (each line begins with the letters "scholarship of teaching and learning") suggests the interconnectedness of these characteristics. In a follow-up to his ISSOTL11 keynote address, Peter Felten looks beyond definitions and takes up the challenge to identify quality as he articulates some clear norms for exemplary work in "Principles of Good Practice in SoTL." (In the next issue of Teaching and Learning Inquiry, we will share our Editorial Board's conversation about these principles and request reader responses in an effort to adopt and adapt them for the journal itself.) Erik Blair's "The Challenge of Contextualising the Scholarship of Teaching and Learning" addresses context, one of the principles in Felten's taxonomy. Instead of expecting data or conclusions that are easily generalizable across contexts, Blair argues that context should always be reported in the analysis, and 
generalization can follow from carefully conducted meta-analyses that also take context into account. Finally, in "On the Margins of SoTL Discourse: An Asian Perspective," Chng Huang Hoon and Peter Looker call attention to the many ways in which SoTL has been expressed as a Western phenomenon, excluding Asian participants not just through the geographical distance but also through SoTL's current methodologies and ideologies.

Here, then, is Volume One, Issue One of Teaching and Learning Inquiry. Thanks to all who have contributed to the development of TLI's vision, and to those who have taken that vision and run with it in such thought-provoking ways in opus one. If this is what the journey is going to be like, we can't wait to take the next steps.

Nancy Chick is Assistant Director of the Center for Teaching and an affiliated faculty member in the English Department at Vanderbilt University.

Gary Poole is the Associate Director of the School of Population Health and a Senior Scholar in the Centre for Health Education Scholarship at the University of British Columbia. 